\title{
Criação do Instituto Superior da Administração Pública e Regulamentação do Estatuto do Pessoal Civil, na Argentina
}

O chefe do Escritótio de Propaganda e Expansão Comercial do Brasil, na Arǵentina, órgão do M.T.I.C., e o Senhor Diretor do Serviço de Documentação dêsse mesmo Miniştério enviaram-nos recortes de periódicos que nos dão conta da criação naquele país de um Instituto Superior de Administração Pública e da Regulamentação do Estatuto do Pessoal Civil.

Tratando-se de assuntos de interêsse para um estudo com. parativo, no campo do direito administrativo, a R.S.P. tem o prazer de reproduzir para os seus leitores o texto integral das notícias acima referidas, aproveitando para agradecer àquelas autoridades o espírito de colaboração demonstrado.

\section{ORGANIZAN EL INSTITUTO DE LA ADMINISTRACIÓN (*)}

SU OBJETO ES MEJORAR LA ESTRUCTURA TÉCNICA SUPERIOR DE LA ADMINISTRACIÓN PÚBLICA

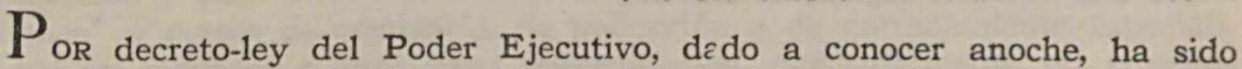
creado el Instituto Superior de la Administración Pública con domicilio legal en la ciudad de Buenos Aires y que tendrá por objeto prestar asistencia técnica y realizar o promover cursos de especialización a fin de mejorar la organización y funcionamiento de la administración del Estado y el nivel de preparación de sus agentes.

Sus funciones serán las siguientes:

Preparar y proveer el asesoramiento técnico que el Poder Ejecutivo y demás organismos de la Nación, provincias y municipalidades del país estimen oportuno encomendarle para la maior solución de los problemas de organización y funcionamiento de la administración pública.

Realizar cursos de capacitación y perfeccionamiento para altos funcionarios de la administración pública, al nivel de posgraduados universitarios, asi como también cursos breves e intensivos de especialización sôbre temas que representen problemas concretos de aquélla.

Proponer al Poder Ejecutivo las normas de dirección, programación y coordenación necesarias para el desarrollo de cursos de capacitación del per-

(\%) In La Prensa, Buenos Aires, 11-II-57. 
sonal de nivel medio e inferior en servicio en los ministerios y demás entidades de la administración nacional.

Realizar y estimular investigaciones y análisis sistemáticos sobre problemas de la edministración pública, con el objeto de promover su solución técnica racional.

Promover entre los funcionarios y entidades públicas el intercambio y difusión de conocimientos y de técnicas y métodos modernos de organización y procedimientos administrativos.

Organizar y mantener cátedras o seminarios especializados, conceder beces y organizar el intercambio de expertos y de trabajadores y publicaciones sobre problemas administrativos, como una forma de acción directa para el progresso de las investigaciones y la aplicación de las técnicas modernas en materia de Administración Pública.

Colaborar con los organismos de la administración nacional, provincial y municipal del país, y eventualmente con los gobiernos de los países vecinos si así lo solicitan, en la realización de los programas de asistencia técnica que en estas materias se aprueben o convengan, con o sin participación de la Administración de Asistencia Técnica de las Naciones Unidas y demás organismos Internacionales.

Colaborar con los institutos, colegios, escuelas y asociaciones científicas del país y del extranjero en cuanto pueda ser útil a los fines del intercambio y difusión de experiencias y conocimientos en la materia.

Orgenizar cursos de capacitación y perfeccionamiento en administración pública para posgraduados universitarios, funcionarios o no, que se inscribam privadamente y den cumplimiento a los requisitos y condiciones que a ese efecto establezca el organismo creado.

\section{Su naturaleza}

El Instituto Superior de la Administración Pública se constituirá con el carácter de estabelecimiento público, con personalidad jurídica y con la autarquia administretiva que se le otorga por el presente decreto y funcionará bajo la superintendencia directa del Poder Ejecutivo.

Su estructura orgánica básica constará de una dirección técnicoadministrativo $\mathrm{y}$, además, comprenderá cursos de administración pública, integrados por el curso superior de administración pública, los de seminario y de adiestramiento especializado y la promoción, asesoramiento y supervisión general de fós de capacitación de nivel medio a cargo de los ministerios.

Igualmente comprenderá al Serviço de Organización y Métodos, destinado a la realización de los trabajos de asesoramiento y preparación de circulares e instrucciones generales, de proyectos y normas sôbre organización o reglamentación عdministrativa, particularmente referidos a los problemas de estructura y procedimientos y el Departamento Biblioteca, Investigaciones y Publicaciones, a cargo de la documentación especializade, la información y estudios técnicos y la preparación y difusión del material didáctico y de.intercambio, incluyendo la publicación de una "Revista de Administración Pública". 


\section{Recursos}

Para el cumplimiento de sus fines, el ISAP contará con los recursos seguientes:

Los créditos y asignaciones que le acuerde el presupuesto general de la Nación y leyes especiales; los ingresos propios que se obtengan de la venta de la revista, de traducciones y publicaciones varias, de la organizeción y atención de cursos especiales, de subvenciones y donaciones y de la provisión de servicios de asesoramiento y asistencia técnica; el "fondo para el asesoramiento y la capacitación administrativa", constituído por la entidad mediante convênio con los ministerios nacionales, gobiernos de provincia, entes autárquicos, municipalidades y empresas del Estado para la provisión de un servicio permanente de asesoramiento en materia de oryanización y métodos de capacitación del persone1; y los créditos y asignaciones que pudieran corresponder a la entidad por su participación activa en el Programa de Asistencia Técnica de las Naciones Unidas.

\section{Dirección y administración}

Su dirección técnica y administrativa estará a cargo de un director designado por el Poder Ejecutivo, quien será secundado en sus funciones por el jefe de la División de Administración y Personal, siendo ambos conjunta y solidariamente responsables por su intervención en administración de fondos, valores y demás bienes de su jurisdicción.

\section{Capacitación de funcionarios}

La capacitación a cargo del Instituto - se establece posteriormente corresponde a los funcionarios de nivel directivo superior dentro de la Administracción y será impartida mediante un "Curso Superior de Administración Pública" y cursos de seminario, de aplicación o de entrenamiento especializados en materias o problemas determinados, perticularmente en aquellos asuntos que requieren perfeccionamiento técnico constante.

E1 ISAP no expedirá titulos de ninguna naturaleza, pero podrá otorgar un certificado de realización del curso superior a los cursantes que lo hubieren completado y presentado y aprobedo una monografia sobre un problema de administración pública conforme a la reglamentación que al efecto se dicte.

Suprimese el Servicio de Asesoramiento y Estudios Técnicos en Administración Pública (SAETAP), dependiente de la Secretaria de Estadística y Asesoramiento de la Presidencia de la Nación.

La Secretaria Genercl de la Presidencia de la Nación propondrá las asignaciones de presupuestos, patrimoniales y de personal que corresponda trasferir de la Presidencia de la Neción al Instituto que se crea por el presente decreto, las que serán aprobadas por decreto del Poder Ejecutivo con intervención del Ministerio de Hacienda.

La Secretaria General de la Presidencia de la Nación propondrá igual. mente, antes de los sesenta dias de la fecha, las medidas necesarias para la instalación del Instituto de Administración Pública y eleverá, conforme a las bases establecidas en el presente decreto, los proyectos de presupuesto, de estructura orgánica, de dotación de personal y. de reglamentación básica 
correspondiente a la primera etapa de organización y funcionamiento de la entidad.

Se tendrá presente que la misión de este Instituto es estrictamente técnica y que su dotación permanente y su estructura orgánica deben reducirse al minimo indispensable, integrándo-se su personal solamente con funcionarios de probada competencia y especialización en la materia.

\section{Los fundamentos}

Entre los fundamentos se señala que es indispensable intensificar $y$ complementar la acción oficial destinada al mejoramiento y economía de los servicios a cargo de la administración del Estado, con objeto de reducir sus gastos y aumentar su eficacia, así como de atenuar los defectos de la burocracia.

Se expresa que "son necesarias las funciones de un instituto tecnico y permanente, destinado a analizar los inconvenientes y las imperfecciones de la administración pública, para promover y facilitar la correcta aplicación de las soluciones mejores y con el esencial propósito de asegurar que la acción de la edministración concuerde efectivamente, con los fundamentos de la Constitución y los fines de la sociedad".

Asimismo, se señala que uno de los problemas más importantes de la aáministración pública es el de mejorar el nivel de preparación técnica de sus funcionarios en servicio, y que para esto es necesario organizer en ella eursos sistemáticos para promover su adiestramiento y capacitación.

\section{EL TEXTO COMPLETO DEL REGLAMENTO DEL ESTATUTO DEL PERSONAL CIVIL DE LA ADMINISTRACIÓN PÚBLICA (*)}

$\mathrm{E}_{\mathrm{L}}$ Poder Ejecutivo nacional ha dado un decreto reglamentando el cuerpo de disposiciones del Estatuto del Personal Civil de la Nación. El texto es ei siguiente: "Visto lo dispuesto por el artículo $99^{\circ}$ del decreto-ley número 6.666 del 17 de junio de 1957 , y de acuerdo con lo propuesto por el Ministerio de Hacienda de la Nación, en orden a la competencia que le confiere el decreto-ley n. ${ }^{\circ}$ 797-58, el presidente provisional de la Nación Argentina decreta:

Artículo $11^{\circ}$ Apruébase el cuerpo de disposiciones adjuntas que constituyen la reglamenteción da los artículos del Estatuto del Personal Civil de la Administración Pública Nacional, aprobado por decreto-ley N. 6.666-57, que en cada caso se indican.

Art. 2..$^{\circ}$ Deróganse las disposiciones anteriores en todo cuanto se opongan a las normas que se dan por la adjunta reglamentación.

Art. 3. ${ }^{\circ}$ Comuniquese, publiquese, dêse a la Dirección General del Boletin Oficial y archívese.

REgLAMENTACIÓN DEL ESTATUTO DEL PERSONAL CIVIL DE LA ADMINISTRACIÓN PÚBLICA NACIONAL

Artículo $10^{\circ}$ Sin reglamentación.

(*) In La Razon, Buenos Aires, 11-II-58. 
Art. 2..$^{\circ}$ Sin reglamentación.

Art. 3. ${ }^{\circ}$ Reglamentación.

I - El ingreso a la Administración Nacional se hará con arreglo a los requisitos establecidos por el Estatuto y a las normas particulares que, ajustadas a las condiciones generales establecidas por la presente reglamentación, dicten las autoridades competentes, de acuerdo a la naturaleza especial de las funciones.

II - La idoneidad se acreditará en orden a la función del cargo o empleo, conforme se indica para cada clase en los puntos siguientes.

III - Son requisitos básicos para ingresar en las clases enunciadas en la reglamentación del artículo $99^{\circ}$, del Estatuto, los siguientes:

Clase A: Personal superior: Pertenecer a las tres (3) primeras categorias de cada uns de los grupos de las clases B y C o del primer grupo de la clase D y obtener la mayor calificación en el concurso de oposición. En caso de que realizado el concurso ninguno de los participantes reúna las condiciones requeridas, deberá realizarse concurso abierto, en el cual podrá intervenir todo agente de la Administración Nacional, como así también personas ajenas a la misma;

Clase B: Personal técnico profesional: Tener título habilitente y ser el mejor, calificado en los concursos de oposición;

Clase C: Personal técnico auxiliar: Poseer título habilitante o tener aprobado el ciclo básico de enseñanza secundaria (3er. año) y acreditar conocimientos de la especialidad cuando no hubieren aspirantes diplomados. Aprobar en ambos casos el examen de competencia y tener más de dieciocho (18) años de edad;

Classe D: Personal administrativo: Haber aprobado el ciclo básico de enseñanza secundaria (3er. año), aprobar el examen de suficiencia, inclusive dactilografia, con no menos de cuarenta y cinco (45) palıbras por minuto al dictado o copia y tener más de dieciocho (18) años de edad. Si ingresaran como "cadetes" deberán tener más de catorce (14) y menos de dieciocho (18) años de edad y tener aprobado el ciclo completo de enseñanza primaria ( $6 .^{\circ}$ grado);

Classe E: Personal obrero y de maestranza: Acreditar la aptitud para el oficio, haber aprobado el $4 .^{\circ}$ grado de enseñanza primaria y tener más de dieciocho (18) años de edad. El que ingrese como aprendiz no podrá ser menor de catorce (14) años, ni mayor de dieciocho (18) años de edad y deberá tener aprobado el $4 .^{\circ}$ grado de enseñanza primaria;

Clase F: Personal de servicio: Acreditar la competencia indispensable para el servicio; tener aprobado el $4 .^{\circ}$ grado de enseñanza primaria (con exclusión de los peones, a quienes se les exigirá saber leer y escribir) y tener más de dieciocho (18) años de edad. Los que ingresen como "aspirantes" deberán tener más de catorce (14) y menos de dieciocho (18) años de edad.

IV - A los efectos del ingreso se entiende por puesto inferior de la carrera correspondente, a la última categoría de cada grupo.

En el caso del personal, cuyas asignaciones se nallan equiparadas a laudos o convenios colectivos de trcbajo, el puesto inferior será aquel que determine dicho laudo para cada especialidad. 
La designación en un organismo centralizado o descentralizado, de personal que reviste en otro de la misma o distinta jurisdicción, no se reputará como nombramiento nuevo, considerándose el caso como transferencia o promoción, según corresponda. Igual tratamiento se dispensará a la desig.. nación como permanente del personal que, por nombramiento expresso de autoridad competente, reviste con carácter accidental durante el término mínimo de un (1) año.

V - No podrá darse posesión de um empleo, hesta tanto la autoridad competente no haya expedido certificación de la salud del aspirante, de la que resulte su aptitud relacionada a la naturaleza de las funciones del cargo correspondente y la no existencia del impedimento previsto en el artículo $4 .^{\circ}$, inciso h), del Estatuto.

VI) Antes de tomar posesión del empleo, el agente designado deberá presentar las declaraciones establecidas en el artículo $6 .^{\circ}$, incisos i) y j) del Estatuto.

VII) La excepción al requisito de nacionalidad argentina, será dispuesta por el Poder Ejecutivo a pedido del respectivo organismo, el que deberá fundarlo en necesidades del servicio.

VIII) El personal que hubiere dejado de pertenecer a la administración por renuncia, podrá ingresar nuevamente siempre que cumpla las condiciones establecidas por el Estatuto y su reglamentación. En tal caso, el reingreso se efectuará en la categoria, clase y grupo en que actuaba al egresar, siempre y cuando haya acreditado méritos suficientes para ello, durante su actuación ancerior.

IX) El agente exonerado de la administración, podrá reingresar, si a tal fin hubiese obtenido su rehabiliteción y satisface los requisitos comunes de ingreso. Dicho reingreso se efectuará, en todos los casos, en la categoria inferior de la carrera, según se definió en el punto IV.

La rehabilitación sólo podrá disponerse a solicitud del interesado. después de los cinco (5) años de aplicada la sanción. En todos los casos, deberá mediar dictamen favorable de la respectiva Jinta de Disciplina.

Art. 5. ${ }^{\circ}$ Reglamentación: E1 nombramiento del personal en forma provisional, a que se refiere el artículo $5 .^{\circ}$ del Estatuto, debe ser efectuado en todos los casos por la autoridad competente. Todo nuevo personal deberá ser calificado en el cuarto mes después de su ingreso a la administración por dos de las instancias mencionadas en el artículo 12 del Estatuto; en cada instancia deberá indicarse en forma expresa si dicho personal debe ser confirmedo o no.

En el caso de personal cuya calificación indicara que no debe ser confirmado, se elevarán los antecedentes respectivos a la autoridad que dispuso su nombramiento, a los efectos de la cancelación del mismo. La confirmación del personal que hubiere obtenido calificación favorable, se operará automáticamente al cumplirse el término de seis (6) meses establecido.

Art. $60^{\circ}$ Reglamentación:

I) Son deberes en relación con lo prescripto en el artículo $6^{\circ}$, incisos a) $y$ b): 
a) Prestar el servicio en el lugar que la Superioridad determine y dedicar a su desempeño el máximo de capacidad y diligencia;

b) Cumplir íntegramente y en forma regular el horario de labor establecido;

c) Ejecutar cumplidamente las directivas superiores;

d) Responder por la eficiencia y rendimiento del personal a sus ordenes;

e) Velar por la conservación de los útiles, objetos y demás bienes que integran el patrimonio del Estado, cualquiera sea su valor;

f) Lievar consigo la credencial que acredite su condición y devolverla al cesar en las funciones;

g) Someterse a las pruebas reglamentarias de competencia;

h) Usar la indumentaria de trabajo que para el caso se establezca;

i) Llevar a conocimiento de la Superioridad, todo acto o procedimiento que pueda causar perjuicio al Estado, o pueda implicar la comisión de delito.

II) Asimismo, es de su deber:

a) Cumplir con sus obligaciones cívicas y militares, acreditándolo ante el superior correspondiente;

b) Declarar bajo juramento la nómina de familiares a su cergo y comunicar, dentro del plazo de treinta (30) dias de producido, el cambio de estado civil o variantes de carácter familiar, acompañando la documentación correspondiente;

c) Mantener permanentemente actualizada la información referente al domicilio;

d) Declarar en los sumarios administrativos;

e) Declerar, bajo juramento, su carácter de jubilado, los cargos oficiales o actividades privadas que desempeñe, a efectos de determinar si están comprendidos en el régimen de incompatibilidades e inhabilidades.

Artículo 7. ${ }^{\circ}$ Reglamentación:

De conformidade con lo prescripto en los artículos $60^{\circ}-$ incisos b), e) y f) y $7 .^{\circ}$ del Estatuto, está prohibido al agente:

a) Realizar gestiones, por conducto de personas extrañas a las que jerárquicamente corresponda, en todo lo relacionado con los derechos y obligaciones establecidos en el Estatuto;

b) Organizar o propiciar, directa o indirectamente, con propósitos políticus o de homenaje o reverancia a funcionatios en activided, suscripciones, adhesiones o contribuciones de personal de la Administración;

c) Recibir homenajes, obsequios, importe de colectas, en dinero o especies, con motivo de sus funciones;

d) Concretar, formalizar y efectuar con o entre el personal, operaciones de crédito;

e) Utilizar, con fines particulares, los elementos de transportes y útiles de trabajo destinados al servicio oficial y los servicios del personal a sus órdenes;

i) Valerse de informaciones relacionadas con ei servicio, de que tenga conocimiento directo o indirecto, para fines ajenos al misno; 
g) Difundir, por cualquier medio y sin la previa autorización superior, informes relativos a la esfera administrativa;

11) Valerse directa o indirectamente de facultades o prerrogativas inherentes a sus funciones, para realizar propaganda o coección política, cualquiera sea el sitio donde ésta se realice. Esta prohibición de realizar propaganda no excluye el ejercicio regular de la acción política que el agente efectúe de acuerdo a sus convicciones, siempre que se desenvuelvan dentro de un marco de mesura y circunspección y no contravenga disposiciones establecidas en el Estatuto.

Art. $8^{\circ}$ Sin reglamentación.

Art. 9. ${ }^{\circ}$ Reglamentación:

I) El personai integrará seis (6) clases básices, cada una de las cuales agrupará a los que realizan tareas de igual naturaleza e importancia similares;

A) Personal superior: Es aquél que desempeña tareas principales de dirección;

B) Personal técnico profesional: Es el que posee títulos universitarios o equivalentes y que se desempeña en funciones específicas de su profesión;

C) Personal técnico auxiliar: Es el que posee título o certificado de carácter técnico de enseñanza media o equivalente, o bien, práctica y competencia demonstradas y que se desempeñe en funciones propias de su especialidad;

D) Personal administrativo: Es el que cumple tareas generales de administración y no está comprendido en las otras clases;

E) Personal obrero y de maestranza: Es aquél que realiza tareas de producción, construcción, reparación y atención y/o conservación de bienes en gुeneral;

F) Personal de servicios: Es el que realiza tareas vinculadas con la atención, custodia y/o limpieza de bienes muebles, immuebles o semovientes o con la atención personal a otros agentes o al público.

II) E1 régimen escalafonario donde se fijarán las condiciones bajo las cuales el personal desarrollará su carrera - inclusive el procedimiento para el cálculo del módulo - a que se refieren los artículos 8..$^{\circ}$ al 12 del Estatuto, será sometido a la aprobación del Poder Ejecutivo, sin que el mismo pueda ser modificado en lapsos menores de tres (3) años de su vigencia.

Art. 10. Reglamentación:

En oportunidad del cambio de clase o grupo previsto en el artículo 10 del Estatuto, el personal conservará su categoria anterior, si ésta fuera igual o superior a la última categoria del nuevo grupo o clase en que pasa a revistar. En el caso de que esta última categoria fuera inferior, será colocado en forma tal que mantenga su situación anterior.

I) Para el cambio de clase serán necesarios los siguientes requisitos:

a) Que exista vacante en la clase a que se desea ascender y que sea necesario cubrirla a juicio de la autoridad competente; 
b) El ingreso se operará en la categoria inferior del grupo respectivo o en el que corresponda por el sueldo;

c) Las vacantes serán discernidas por concurso.

II) Para el cambio de grupo se cumplirán los siguientes extremos:

a) Que exista vacante en el grupo a que se desea ascender y que sea necesario cubrirla a juicio de autoridad competente;

b) Que el agente ocupe el primer lugar en el orden de prioridad entre el personal del grupo a que pertenece;

c) E1 ingreso se operará en la categoria inferior del grupo respectivo o en el que corresponda por el sueldo.

Art. 11. Sin reglamentación.

Art. 12. Sin reglamentación.

Art. 13. Reglamentación:

La retención de categoria a que se refieren los artículos 13 y 14 del Estatuto, será facultativa del empleado en todos los casos en que el nombramiento en un nuevo cargo emane del Poder Ejecutivo o de autoridad competente y debe hacerse constar en forma expresa.

Art. 14. Reglamentación:

Al personal a que se refiere el artículo 14 del Estatuto, en el momento de ser designado candideto, se le acordará licencia sin goce de haberes. En caso de ser elegido, deberá efectuar la opción a que se refiere la reglementación del articulo 13 del Estatuto. Se no resultar electo, deberá reintegrarse a sus funciones dentro de los diez (10) dias.

Art. 15. Sin reglamentación.

Art. 16. Reglamentación:

Los Organismos dependientes del Poder Ejecutivo Nacional, deben determinar en forma expressa las menciones especiales que fundamentan el derecho a ia bonificación establecida en el artículo 16 del Estatuto. La bonificación será igual al $10 \%$ de la celificación inmediata posterior del empleado, a la cual deberá adicionarse el porcentaje estipulado como premio.

Art. 17. Sin reglamentación.

Art. 18. Sin reglamentación.

Art. 19. Sin reglamentación.

Art. 20. Reglamentación:

El personal en condiciones de obtener jubilación o retiro voluntario, tendrá derecho a permanecer en el empleo con goce de haberes, durante los seis (6) meses siguientes a la fecha de haber sido notificado o manifestado su voluntad de jubilarse o retirarse.

Art. 21. Reglamentación:

E1 personal que hubiere obtenido los beneficios del retiro voluntario, sólo podrá reingresar a la Administración Nacionel, cuando no hubieren transcurrido más de cinco (5) años de su egreso y sus condiciones lo señalen como un elemento de utilidad para la misma, de acuerdo con los antecedentes de su actuación administrativa anterior. 
E1 reingreso, en tal caso, se efectuará en las mismas condiciones que establece el punto VIII) de la reglamentación del artículo $3 .^{\circ}$ del Estatuto

Art. 22. Sin reglamentación.

Art. 23. Reglamentación:

Los reclamos en casos de sanciones disciplinares que no requieran sumarios, a que se refiere el artículo 23 del Estatuto, se deducirán por la via jerárquica común en forma de asegurar al agente una segunda instancia.

\section{Art. 24. Reglamentación:}

E1 recurso será presentado por intermedio de los organismos competentes, dependientes del Poder Ejecutivo Nacional.

Art. 25. Reglımentación:

I) La defensa de la Nación en los juicios que se promuevam con motivo del recurso acordado por el Estatuto, se hará por intermedio de los representantes que determinen las disposiciones vigentes sôbre el particular en los organismos dependientes del Poder Ejecutivo Nacional.

II) En la oportunidad de la remisión por la autoridad administrativa al Tribunal de las actuaciones a que se refiere el artículo 25 del Estatuto, aquella deberá comunicar la existencia del recurso al organismo por cuyo intermedio se realice la defensa de la Nación para su intervención y a la Dirección General de Administración a los efectos previstos en el artículo 28 del Estatuto.

Art. 26. Sin reglamentación.

Art. 27. Sin reglamentación.

Art. 28. Sin reglamentación.

Art. 29. Reglamentación:

El ex agente que hubiera optado por la indemnización prevista por el artículo 29 del Estatuto, no podrá reingresar a la Administración antes de los cinco (5) años desde su cese o si tuviere más de 50 años de edad. A estos efectos se seguirá igual procedimiento que el previsto en la reglamentación del articulo 21 del Estatuto.

Art. 30. Sin reglamentación.

Art. 31. Reglamentación:

I) La indemnización por gastos de trasledo del agente y de la familia a sua cargo a la fecha de producido éste, por cambio de destino que obedezca a necesidades del servicio e importe una real y efectiva modificación de domicilio a una distancia superior a cincuenta (50) kilómetros del anterior, compensará las erogaciones que por tal concepto se realicen efectivamente, dentro de las cantidades máximas que rijan.

II) E1 personal que no haga efectivo el traslado de la familia a su cargo al nuevo destino, dentro del término de um (1) año desde la fecha de ordenado su cambio de destino, sin causa de fuerza mayor debidamente comprobsda, perderá todo derecho a la indemnización pertinente. 
III) E1 personal trasladado a su pedido o por permuta, no tendrá derecho a indemnización por cambio de destino.

IV) Los gastos originados en o por actos del servicio, determinan indemnizaciones en concepto de viáticos, movilidad gastos de comida y reintegro de otros gastos, conforme a les escalas y normas que rijan la materia.

V) Se indemnizará también en los siguientes casos conforme las disposiciones que rijan la materia:

a) Traslado por enfermedad: cuando se trate de personal destacado o en comisión del servicio, fuera del asiento habitual de sus funciones y la naturaleza de la enfermedad, debidamente certificada por autoridad sanitaria oficial, haga necesario el trasledo, siempre que no esté a cargo de organismos asistenciales del personal;

b) Traslado de los restos del agente fallecido: hasta la localidad donde indiquen los deudos, dentro del territorio nacional;

c) Trasledo del agente que dejare de prestar servicios en la Administración: desde el lugar donde fué destacado hasta el asiento habitual de la familia.

VI) Cuando en actos del servicio el personal experimentase un daño patrimonial, tendrá derecho a una indemnizeción equivalente al deterioro o destrucción de la cosa, siempre que no mediare culpa ni negligencia del agente.

VII) E1 agente que sufriera una incapacidad parcial y permanente como consecuencia de una enfermedad profesional o acidente del trabajo y que pudiera reintegrarse al servicio, no podrá ser dado de baja, debiéndosele asignar otras tareas acordes con sus aptidudes fisicas y en lo posible dentro de su misma clase o grupo.

VIII) En caso de muerte del agente, por enfermedad profesional o accidente del trabajo, sus derecho-habientes deberán percibir la indemnización establecida en la ley $\mathrm{N}^{\circ} 9.688$, sin perjuicio de los beneficios que acuerdan las leyes de previsión.

Los derecho-habientes a que se refiere la presente disposición son los enunciados en el artículo 8 de la mencionada ley.

IX) La denuncia del accidente del trabajo, deberá efectuarse ante la autoridad administrativa del organismo en que se desempeñe el agente, dentro de los cinco (5) dias de producido.

Art. 32. Sin reglamentación.

Art. 33. Sin reglamentación.

Art. 34. Reglamentación:

La postergación en el ascenso poḍá disponerse hasta un máximo de dos (2) períocios. La retrogradación alcanzará una (1) categoria como máximo en cada caso.

Art. 35. Reglamenteción:

I) Las suspensiones tanto correctivas como preventivas se harán efectivas sin prestación de servicios y sin percepción de haberes (arts. 35 e 39 del Estatuto). 
II) En cada organismo dependiente del Poder Ejecutivo Nacional, se determinarán las autoridades que, en las respectivas jurisdicciones, aplicarán las medidas disciplinarias de apercibimiento y suspensión hasta diez (10) dias. La suspensión meyor de diez (10) dias y la postergación en el ascenso, serán dispuestas por las autoridades superiores de los organismos dependientes del Poder Ejecutivo.

La retrogradación de categoria, la cesantia y la exoneración, serán aplicables exclusivamente por el Poder Ejecutivo o autoridad expresamente facultada para ello.

Art. 36. Reglamentación:

I) El personal que sin causa justificada incurriera en incumplimiento del horario fijado, se hará pasible de las siguientes sanciones: primer a quinto incumplimiento en el año: sin sanción; sexto, primer apercibimiento; séptimo, segundo apercibimiento; octavo, tercer apercibimiento; noveno, un dia de suspensión; décimo, dos dias de suspensión.

De sobrepasarse el límite de diez (10) faltas de puntualidad en el año deberán elevarse los antecedentes respectivos a la superioridad a fin de imponer, en mérito a los mismos, la sanción disciplinaria que estime corresponder.

II) E1 persons1 que sin causa justificada incurra en inasistencias, e hará pasiblę de las siguientes sanciones: primera inasistencia en el año, apercibimiento; segunda inasistencia, un dia de suspensión; tercera inasistencia, un día de suspensión; cuarta inasistencia, dos díes de suspensión; quinta inasistencia, dos días de suspensión; sexta inasistencia, tres días de suspensión; séptima inasistencia, tres días de supensión; octava inasistencia, cuatro días de suspensión; novena inasistencia, cinco días de suspensión; décima inasistencia, seis días de suspensión. El cómputo de las faltas se hará por cada día de inasistencia y las suspensiones son sin perjuicio del descuento de haberes correspondientes a las inasistenciais incurridas.

Art. 37. Sin reglamentación.

Art. 38. Sin reglamentación.

Art. 39. Reglamentación:

I) Cuando el agente se encontrare privado de la libertad o sometido a proceso criminal por hechos ajenos al servicio, será suspendido preventivamente en su cargo administrativo. La suspensión durará, en el primer caso, hasta que el agente recobre la liberdade y en el segundo, hasta que demuestre su inculpabilidad con el testimonio de la sentencia firme respectiva.

II) En los casos en que el personal fuera sancionado con exoneración o cesandía, no tendrá derecho a la percepción de los haberes correspondientes al lapso durante el cual permaneció suspendido.

Art. 40. Sin reglamentación.

Art. 41. Reglamentación:

I) E1 sumario se iniciará de oficio o por denuncia escrita y debidamente ratificada. La instrucción del sumerio será ordenada inmediatamente de conucido el hecho por las autoridades que en cada jurisdicción se determine. 
II) La denuncia deberá consignar una relación circunstanciada del hecho denuncicdo, con expresión de tiempo, lugar medios empleados y actuaciones administrativas en que constare, exigiêndose también al denunciante que constituya domicilio. E1 denunciante deberá aportar, asimismo, los elementos de prueba correspondientes, si los tuviera.

III) Dispuesta la formación del sumario por la autoridad a que se refiere el punto I), ésta designará en el mismo acto al instructor, a quien se le remitirán todos los elementos y antecedentes del caso. El instructor debe pertenecer a la misma jurisdicción en la que se ha producido el hecho.

Asimismo, a propuesta del instructor, se designará un secretario, llamado a dar fe de todos los actos, declaraciones y providencias, actas y demás actuaciones sumariales.

IV) Toda actuación o providencia incorporada al sumario, deberá ser debidamente foliada, consignándose lugar, fecha y hora, con aclaración de firmas y en lc posible, serán hechas mediante escritura a máquina.

Las raspaduras, enmiendas o interlineaciones en que se hubiera incurrido durante el acto, serán salvadas al pie del acta y antes de las respectivas firmas. No podrán dejarse claros e espacios de ninguna naturaleza, antes de las firmas.

V) El acta del interrogatorio será firmada por los intervinientes en todas las fojas, inđicándose en la última el número de fojas útiles que comprende la declaración. Si el declarante no oudiera, no supiere o no quisiera firmar, se hará constar al pie de la declaración.

VI) Todos los interrogetorios deberán encabezarse con indicación del lugar, fecha y hora, nombre y apellido del compareciente, dentificación, ocupación, estado civil, domicilio y constancia de habérsele requerido juramento de decir verdad de cuanto le fuera preguntado.

Al imputado o presunto autor o responsable, no podrá exigirsele el juramento expresado.

VII) Las preguntas serán siempre claras y precisas y relacionadas con el asunto que se investiga.

El declarante dictará por sí mismo sus declaraciones, pero no podrá traerlas escritas de antemano.

VIII) Concluído el acto y si el interrogado se negara a leer su declaración, el sumariante procederá a su lectura en voz alta y clara, dejándose expresa constancia de ello. E1 declarante deberá manifestar si se ratifica de su contenido o si por el contrario, tiene algo que añadir o enmendar. Se no se ratificara en todo o en parte, se herá constar en forma el hecho y las causas invocadas, pero en ningún caso se testará lo escrito, sino que las nuevas manifestaciones se agregarán a continuación de lo actuado, relacionando cada punto con lo que conste más arriba y sea objeto de modificación. En este acto, el instructor le hará saber que puede declarar sobre el asunto curntas veces lo considere conveniente y el estado del sumario lo permita.

IX) El sumariante practicará las diligencias propuestas por el denunciante o el inculpado. En caso de no considerarlas procedentes, deberá dejar const $\varepsilon$ ncia fundada de su negativa. 
X) Cuando las declaraciones obtenidas en un sumario discordarem acerca de algún hecho o circunstancia que convenga dilucidar, se tratará, en los interrogatorios, de aclarar les discrepancias y, en último caso, el instructor procederá a efectuar los careos correspondientes.

XI) E1 instructor deberá incorporar al sumario todo dato, antecedente, instrumento o información que del curso de los interrogatorios, surja como necesario o conveniente para el esclarecimiento de los hechos o individualización de los responsables. A tal efecto y en la forma que corresponda, podrá recabar el concurso de los demás organismos de la Administración. cusados:

XII) Los instructores deberán excusarse y podrán a su vez ser re-

a) Cuando medie parentesco por consanguinidad hasta cuarto grado o segundo de afinidad con el sumariado o con el denunciante;

b) Cuando en oportunided anterior hubiesen sido denunciantes o denunciados por alguna de las partes; parts;

c) Cuando tengan amistad o enemistad manifiesta con alguna de las

d) Cuando tengan relaciones de intereses o sean acreedores o deudores de algunos de ellos;

e) Cuando tengan relación de dependencia con los mismos.

XIII) Cuando el instructor disponga el cierre del sumario, formulará las conclusiones que resulten de lo actuado, luego de lo cual dará vista al imputado pॄra que presente su alegato de defensa, sobre la base concreta de las imputaciones y cargos consignados en el informe del instructor, dentro del término establecido en el artículo 41 del Estatuto. A ese fin, el imputado podrá ser asistido por un letrado.

Dentro de los diez (10) días de concluídas las actuaciones, el instructor las remitirá a la Junta de Disciplina, acompañadas del legajo del agente sumariado y dará cuenta de ello a la autoridad que dispuso la instrucción del sumario.

XIV) La substanciación de los sumarios administrativos que pudieran configura $\mathrm{r}$ delitos y la aplicación de las sanciones pertinentes en el orden administrativo, serán independientes de la causa criminal, con sujeción a las siguientes normas:

a) Cuando en un sumario administrativo surgieran indicios de haberes cometido un delito que dé nacimiento a la acción pública, se procederá a formular la denuncia correspondiente, de acuerdo a lo previsto por el artículo 164 del Código de Procedimientos en lo Criminal;

b) En el supuesto aludido en a), sólo podrá proseguirse la substanciación del sumario a los efectos de establecer la conducta del agente en el orden administrativo y determinar si corresponde la aplicación de sanciones disciplinarias, pero pendiente la causa criminal, no podrá dictarse resolución absolutoria;

c) La resolución que se dicte en la causa criminal no influirá, necesariamente, en las decisiones que adopte la administración y el sobreseimiento 
provisional o definitivo, asi como la absolución en dicha causa, no habilitará al agente para continuar en el servicio civil si el mismo fuera sancionado en el sumario administrativo.

XV) La confesión del acusado hace proeba en su contra y podrá con ello darse por terminada la instrucción, salvo que las circunstancias que rodean el hecho investigado y otros elementos de juicio documentados en la misma, dieran base para su prosecución a los efectos de mejor esclarecimiento.

XVI) E1 personal no podrá ser sumariado después de haber transcurrido cinco (5) años de cometida la falta que se le imputa, salvo que se trate de actos o hechos que lesionen el patrimonio del Estado.

XVII) En la instrucción deberá actuar personalmente el sumariado, sin perjuicio de su derecho a ser asistido por letrado en la forma autorizada por el punto XIII).

XVIII) A los efectos de que comprezca a prestar declaración el imputado, deberá ser notificado en legal forma; si no obstante ello no compareciere, se lo notificará por segunda y última vez. No presentándose, sin justificar la causa, el instructor deberá proseguir el sumario con el fin de reunir todos los elementos de prueba tendientes a esclarecer el hecho investig̨do.

Concluídas estas diligencias, el sumario quedará paralizado y será elevado a la Junta de Disciplina. En este estado, dicha Junta determinará si corresponde aplicar las sanciones previstas en los artículos 37 y 38 del Estatuto.

Sin perjuicio de lo expuesto, aclárase que la no concurrencia, su silencio o negativa a declarar, no harán presunción alguna en contra del agente en el sumario respectivo, salvo que éste se instruyera por abandono del servicio, en cuyo caso, la no concurrencia a las notificaciones confirmará la comisión del hecho.

Art. 42. Sin reglamentación.

Art. 43. Reglamentación:

I) La Junta de Disciplina se constituirá durante los treinta (30) días subsiguientes a la aprobación de la presente reglamentación y la Junta de Calificaciones, dentro de igual lapso, contado desde la fecha en que se apruebe el escalafón.

II) Los dos (2) miembros titulares y los dos (2) suplentes que representarán al personal en la 'iunta de Disciplina y en Junta de Calificaciones, serán elegidos por voto secreto de todo el personal, a simple pluralidad de sufragios. Durarán el período previsto por el artículo 43 del Estatuto, y no podrán ser reelegidos para el período siguiente. La elección será efectuada por lo menos con treinta (30) días de antelación al término del mandato de los anteriores representantes.

III) Durante su gestión, los miembros titulares de la Junta de Disciplina y de la Junta de Calificaciones, o los suplentes, en su caso, cualquiera sea el origen de su designación, serán relevados de sus funciones administrativas en la medida necesaria, pero conservarán su condición estatutaria, con todos los derechos y obligaciones que ella determina. 
Art. 44. Reglamentación:

La Junta de Disciplina se pronunciará, dentro del término determinado por el artículo 44 del Estatuto, aconsejando:

a) La ampliación del sumario por el mismo u otro instructor, o la adopción de otras medidas para mejor proveer;

b) La declaración de inexistencia de responsabilidad disciplinaria;

c) La declaración de existencia de responsabilidad, fundada en el hecho o hechos probados, sus características, la imputabilidad de los agentes respectivos y la sanción a aplicar.

Producido el dictamen, la Junta de Disciplina lo elevará con las actuanciones respectivas, a la autoridad que corresponda para que ésta resuelva.

Art. 45. Reglamentación:

I) Los reclamos, fundados y documentados, en materia de calificaciones, ascensos, menciones y orden de mérito, deberán presentarse ante el Ministerio u Organismo competente, dentro de los cinco (5) días de la notificación.

Con el informe pertinente, las actuaciones serán remitidas a la Junta de Calificaciones, dentro de los diez (10) días de presentado el reclamo.

II) La Junta de Calificaciones podrá disponer la comparencia del recurrente, el cual deberá someterse a les pruebas de competencia relacionadas con la función desempeñada que aquélla ordenara. La negativa a esta medida implicará desistimiento del recurso. 